This is an electronic reprint of the original article. This reprint may differ from the original in pagination and typographic detail.

Author(s): $\quad$ Cheung, Stephen S.; Mutanen, Niina E.; Karinen, Heikki M.; Koponen, Anne S.; Kyröläinen, Heikki; Tikkanen, Heikki O.; Peltonen, Juha E.

Title: Ventilatory Chemosensitivity, Cerebral and Muscle Oxygenation, and Total Hemoglobin Mass Before and After a 72-Day Mt. Everest Expedition

Year: $\quad 2014$

Version:

Please cite the original version:

Cheung, S. S., Mutanen, N. E., Karinen, H. M., Koponen, A. S., Kyröläinen, H., Tikkanen, H. O., \& Peltonen, J. E. (2014). Ventilatory Chemosensitivity, Cerebral and Muscle Oxygenation, and Total Hemoglobin Mass Before and After a 72-Day Mt. Everest Expedition. High Altitude Medicine and Biology, 15(3), 331-340.

https://doi.org/10.1089/ham.2013.1153

All material supplied via JYX is protected by copyright and other intellectual property rights, and duplication or sale of all or part of any of the repository collections is not permitted, except that material may be duplicated by you for your research use or educational purposes in electronic or print form. You must obtain permission for any other use. Electronic or print copies may not be offered, whether for sale or otherwise to anyone who is not an authorised user. 


\title{
Ventilatory Chemosensitivity, Cerebral and Muscle Oxygenation, and Total Hemoglobin Mass Before and After a 72-Day Mt. Everest Expedition
}

\author{
Stephen S. Cheung, ${ }^{1,2}$ Niina E. Mutanen, ${ }^{2,3}$ Heikki M. Karinen, ${ }^{2,4}$ Anne S. Koponen, ${ }^{2}$ \\ Heikki Kyröläinen, ${ }^{5}$ Heikki O. Tikkanen, ${ }^{2,3}$ and Juha E. Peltonen ${ }^{2,3}$
}

\section{Abstract}

Cheung, Stephen S, Niina E. Mutanen, Heikki M. Karinen, Anne S. Koponen, Heikki Kyröläinen, Heikki O. Tikkanen, and Juha E. Peltonen. Ventilatory chemosensitivity, cerebral and muscle oxygenation, and total hemoglobin mass before and after a 72-day Mt. Everest expedition. High Alt Med Biol 15:331-340, 2014.Background: We investigated the effects of chronic hypobaric hypoxic acclimatization, performed over the course of a 72-day self-supported Everest expedition, on ventilatory chemosensitivity, arterial saturation, and tissue oxygenation adaptation along with total hemoglobin mass (tHb-mass) in nine experienced climbers (age $37 \pm 6$ years, $\dot{\mathrm{V} O}{ }_{2 \text { peak }} 55 \pm 7 \mathrm{~mL} \cdot \mathrm{kg}^{-1} \cdot \mathrm{min}^{-1}$ ).

Methods: Exercise-hypoxia tolerance was tested using a constant treadmill exercise of $5.5 \mathrm{~km} \cdot \mathrm{h}^{-1}$ at $3.8 \%$ grade (mimicking exertion at altitude) with 3-min steps of progressive normobaric poikilocapnic hypoxia. Breath-by-breath ventilatory responses, $\mathrm{SpO}_{2}$, and cerebral (frontal cortex) and active muscle (vastus lateralis) oxygenation were measured throughout. Acute hypoxic ventilatory response (AHVR) was determined by linear regression slope of ventilation vs. $\mathrm{SpO}_{2}$. PRE and POST ( $<15$ days) expedition, tHb-mass was measured using carbon monoxide-rebreathing.

Results: Post-expedition, exercise-hypoxia tolerance improved (11:32 $\pm 3: 57$ to $16: 30 \pm 2: 09 \mathrm{~min}, p<0.01)$. AHVR was elevated $\left(1.25 \pm 0.33\right.$ to $\left.1.63 \pm 0.38 \mathrm{~L} \cdot \min ^{-1} \% \%^{-1} \mathrm{Spo}_{2}, p<0.05\right) . \mathrm{Spo}_{2}$ decreased throughout exercise-hypoxia in both trials, but was preserved at higher values at $4800 \mathrm{~m}$ post-expedition. Cerebral oxygenation decreased progressively with increasing exercise-hypoxia in both trials, with a lower level of deoxyhemoglobin POST at 2400, 3500 and $4800 \mathrm{~m}$. Muscle oxygenation also decreased throughout exercisehypoxia, with similar patterns PRE and POST. No relationship was observed between the slope of AHVR and cerebral or muscle oxygenation either PRE or POST. Absolute tHb-mass response exhibited great individual variation with a nonsignificant $5.4 \%$ increasing trend post-expedition $(975 \pm 154 \mathrm{~g}$ PRE and $1025 \pm 124 \mathrm{~g}$ POST, $p=0.17)$.

Conclusions: We conclude that adaptation to chronic hypoxia during a climbing expedition to Mt. Everest will increase hypoxic tolerance, AHVR, and cerebral but not muscle oxygenation, as measured during simulated acute hypoxia at sea level. However, tHb-mass did not increase significantly and improvement in cerebral oxygenation was not associated with the change in AHVR.

Key Words: acute hypoxic ventilatory response; altitude adaptation; chronic hypoxia; climbers; extreme altitude; NIRS.

\footnotetext{
${ }^{1}$ Environmental Ergonomics Laboratory, Department of Kinesiology, Brock University, St. Catharines, Ontario, Canada

${ }^{2}$ Department of Sports and Exercise Medicine, Institute of Clinical Medicine, University of Helsinki, Helsinki, Finland.

${ }^{3}$ Foundation for Sports and Exercise Medicine, Clinic for Sports and Exercise Medicine, Helsinki, Finland.

${ }^{4}$ Unit for Occupational Health, Department of Health Sciences, University of Tampere, Tampere, Finland.

${ }^{5}$ Department of Biology of Physical Activity, University of Jyväskylä, Finland.
} 


\section{Introduction}

A CUTE EXPOSURE TO ALTITUDE significantly decreases endurance exercise performance, but this decrement may be reversed with chronic exposure and acclimatization through a wide range of physiological mechanisms (Moore et al., 1998; Fulco et al., 2013). Ventilation rapidly increases upon acute hypoxic exposure, and this hypoxic ventilatory response (HVR) is generally presumed to enable better performance at altitude by maintaining arterial oxygen saturation levels (Schoene et al., 1984; Masuyama et al., 1986). Alternatively, a strong HVR has also been proposed to be a negative adaptation that reduces ventilatory reserve at altitude (Bernardi et al., 2006), while hyperventilation and the resultant hypocapnia may reduce cerebral blood flow (Poulin et al., 2002; Ainslie and Poulin, 2004).

Cerebral oxygenation does not appear to be a critical threshold limiter for self-paced (Billaut et al., 2010) or maximal exercise capacity (Subudhi et al., 2007) in normoxia. However, when combined with the additional stress of acute or chronic exposure to hypoxia, cerebral oxygenation rose and exercise tolerance was prolonged when hyperoxia was induced near the point of exhaustion (Subudhi et al., 2008), suggesting that oxygen availability in the brain may become critical limiters to performance in hypoxia. Comparing the responses to isocapnic hypoxia with normoxia while resting (Peltonen et al., 2007) or to poikilocapnic hypoxia during graded exercise to exhaustion (Peltonen et al., 2009), cerebral oxygenation tended to decrease at a greater rate during hypoxia, although no single threshold concurrent with voluntary fatigue was apparent; muscle oxygenation levels decreased at a similar rate in both normoxia and hypoxia. Similar observations were reported by Ainslie et al. (2008), with a decrease in cerebral oxygenation but less change in muscle oxygenation during hypoxic exercise following either 10-12 days of intermittent hypoxia or chronic exposure to $1500 \mathrm{~m}$ elevation. In addition, arterial oxygen saturation levels may serve as a predictor for acute mountain sickness (Karinen et al., 2010). Fulco et al. (2011) reported improved arterial oxygen saturation levels during sleep to be reflected in improvements in AMS symptoms upon awakening but not on AMS or exercise performance for the remainder of the day. It would be of interest to explore whether chronic altitude exposure alters arterial oxygen saturation levels during exercise, along with its relationship to tissue oxygenation.

Another commonly proposed adaptation with chronic hypoxic exposure is an elevation in the release of erythropoietin (EPO) (Pugh, 1964), potentially stimulating the production of red blood cells and ultimately enabling greater oxygen delivery to the body for a given cardiac output (Gunga et al., 2007). Pugh (1964) reported an increase in [EPO] and hemoglobin concentration $[\mathrm{Hb}]$ with prolonged expeditions above $5500 \mathrm{~m}$. Similarly, Savourey et al. (1996) reported an increase in [EPO] in nine climbers following a 62-day Himalayan expedition, which persisted for up to a month upon return to sea level. However, [EPO] and [Hb] are highly influenced by plasma and blood volume, which can alter rapidly and transiently upon ascent or return to sea level (Tannheimer et al., 2010).

In contrast, total hemoglobin mass (tHb-mass) is the actual endpoint hematological result of hypoxic exposure. With prolonged moderate altitude $(2300-3000 \mathrm{~m})$ exposure a progressive increase of approximately $1.1 \%$ in tHb-mass for each
$100 \mathrm{~h}$ of hypoxic exposure over 2 weeks of moderate altitude has been reported in a meta-analysis (Gore et al., 2013), with a proposed ceiling increase across multiple studies of approximately $7 \%$ after $\sim 500 \mathrm{~h}$ (Saunders et al., 2009). The actual measurement of $\mathrm{tHb}$-mass before and following self-supported high-altitude climbing expeditions has not been previously reported. Furthermore, wide inter-individual variability in hematological responses to moderate altitude exposure has also been reported, with distinct responders and nonresponders in [EPO], red cell volume, and aerobic capacity following $30 \mathrm{~h}$ of live-high-train-low altitude exposure (Chapman et al., 1998); similarly, highly variable tHb-mass responses also occur in response to live-high-train-high altitude exposures (Saunders et al., 2009b). The variability in tHb-mass responses to extreme altitude has not been investigated.

The aim of the present study was to examine the physiological responses to an extreme high-altitude mountaineering expedition, focusing on the integrative adaptations in ventilatory responses, arterial saturation, cerebral and active muscle oxygenation, and total hemoglobin mass. Before and following a 72-day self-supported Everest mountaineering expedition, a constant treadmill exercise protocol with an incremental poikilocapnic hypoxic challenge was performed, along with measurement of total hemoglobin mass. We hypothesized that exercise-hypoxia tolerance would be improved post-expedition. Furthermore, we hypothesized the following to be contributing mechanisms:

1. Ventilatory chemosensitivity would be enhanced, with an elevated acute hypoxic ventilatory response postexpedition.

2. Arterial $\mathrm{O}_{2}$ saturation would be higher post-expedition at a given simulated altitude due to increased acute hypoxic ventilatory response.

3. Cerebral and active muscle (vastus lateralis) oxygenation would be maintained at a higher level post-expedition due to increased hypoxic ventilatory response.

4. Total hemoglobin mass would be increased postexpedition.

\section{Materials and Methods}

\section{Participants}

This study was approved by the institutional research board and the University of Helsinki ethics committee, and it was conducted according to the Declaration of Helsinki. Nine healthy males (height $179 \pm 7 \mathrm{~cm}$, body mass $80.4 \pm 8.6 \mathrm{~kg}$, age $37 \pm 6$ years, body mass index $25.1 \pm 2.6, \mathrm{VO}_{2 \text { peak }}$ $55 \pm 7 \mathrm{~mL} \cdot \mathrm{kg}^{-1} \cdot \mathrm{min}^{-1}$ ) took part in the study after providing informed written consent. The participants were experienced climbers and members of the Airborne Ranger Club of Finland taking part in an expedition to summit Mount Everest. Medical screening by a physician, including standard 12-lead ECG at rest and flow-volume spirometry (Medikro Spiro 2000, Medikro, Kuopio, Finland), was performed before the start of the study. None of the participants had a history of cardiovascular, respiratory, or musculoskeletal diseases, and all were free of medication.

\section{Climbing Expedition}

Expedition day 1 was defined as the day of arrival in Kathmandu. At the beginning and at the end of the expedition, 
the climbers spent 5 and 6 days, respectively, in Kathmandu at an altitude of $1300 \mathrm{~m}$. The climbers first hiked to the base camp of Mount Everest $(5300 \mathrm{~m})$ and reached progressively higher camps at various altitudes. Four out of nine climbers reached the Everest summit $(8848 \mathrm{~m})$, all with oxygen supplementation beginning at approximately $8100 \mathrm{~m}$, after 59 days. Each climber reached at least the altitude of $7100 \mathrm{~m}$. For all participants, the expedition lasted 72 days in total, including a 2-month stay at an altitude above $2500 \mathrm{~m}$ from which 49 days were at or above $5300 \mathrm{~m}$. The expedition was self-supported, in that no porters were used above $5300 \mathrm{~m}$ and the nine climbers carried all of their own gear. Thus, overall activity levels and energy expenditure were much higher than typical supported mountaineering expeditions. For example, each climber performed 9-12 traverses of the Khumbu Icefall compared to the typical 2-3 traverses for a supported expedition. In general, all climbers experienced mild acute mountain sickness (3-4 on the Lake Louise Scale) upon initial arrival at $5300 \mathrm{~m}$, but these symptoms faded and did not recur at higher altitudes.

\section{Exercise-hypoxia protocol}

The experimental protocol was performed twice with each participant, on average 12 days before (PRE, range 6-20 days) and 13 days (POST, range 9-15 days) after the expedition descended to $3000 \mathrm{~m}$. Measurements were performed at sea level (Helsinki) at ambient temperature and humidity for both pre- and post-tests. For both PRE and POST, the participants arrived at the laboratory 3-4 hours after a meal and after $24 \mathrm{~h}$ without caffeine or alcohol ingestion, along with no physical exercise for at least $12 \mathrm{~h}$.

The protocol consisted of walking on a treadmill with a constant load (speed $5.5 \mathrm{~km} \cdot \mathrm{h}^{-1}$, grade $3.8 \%$ ) while being exposed to 3-min stages of increasing hypoxic stimulus $\left(\mathrm{P}_{\mathrm{I}} \mathrm{O}_{2}=159,120,105,90,86,80,75,69 \mathrm{mmHg}\right)$ to simulate the different camp altitudes during an ascent to Mt. Everest $(0,2400,3500,4800,5200,5800,6400,7100 \mathrm{~m}$, respectively). The actual hypoxic exposure was preceded by 3 min of rest while the participant stood relaxed and breathed normoxic room air through a mask. The participant then began a 3 min baseline walking in normoxia, after which hypoxic breathing was started. The duration of each hypoxic step ( 3 min) was chosen to ensure enough time for the adjustment of gas mixture and for the measured variables to settle to a new level of $\mathrm{P}_{\mathrm{I}} \mathrm{O}_{2}$, based on $6 \mathrm{x}$ the time constant $(\tau)$ for rate of oxygen uptake $\left(\dot{\mathrm{VO}}_{2}\right)$ and heart rate of $\sim 30 \mathrm{~s}$. At the same time, a total hypoxic duration $<20$ min was chosen to minimize possible hypoxic ventilatory decline during longer exposures (Kolb et al., 2004).

The normobaric, poikilocapnic, hypoxic protocol was achieved with a custom-designed flow meter. The hypoxic stimulus was varied by reducing the inspired $\mathrm{O}_{2}$ concentration, while the total pressure of gas mixture was kept normobaric by simultaneously increasing $\mathrm{N}_{2}$ concentration. The apparatus consisted of gas bottles $\left(\mathrm{O}_{2}\right.$ and $\left.\mathrm{N}_{2}\right)$, adjustment device for $\mathrm{O}_{2}$ and $\mathrm{N}_{2}$ gas flow, mixing chamber for inspiratory gases and a tube to conduct gases from the mixing chamber to valve. A three-way valve directed either normoxic room air or $\mathrm{O}_{2} / \mathrm{N}_{2}$ mixtures to the inspiratory port of a non-rebreathing valve. The adjustments of inspiratory $\mathrm{O}_{2}$ and $\mathrm{N}_{2}$ gas flow were made by comparing the measured fractional gas concentration of inspired $\mathrm{O}_{2}$ and $\mathrm{N}_{2}$ with the desired values and adjusting the gas mixture manually as needed. To ensure participant well-being, exercise was immediately terminated upon voluntary decision, if the participant started to exhibit impaired coordination of walking, or if arterial $\mathrm{O}_{2}$ saturation $\left(\mathrm{SpO}_{2}\right)$ fell to an ethically-imposed limit of $62 \%$. Immediately after the termination of the test, the participants were given $100 \% \mathrm{O}_{2}$ via respiratory mask to speed up the recovery of $\mathrm{SpO}_{2}$ to the normal level.

\section{Cardiorespiratory measures}

$\mathrm{SpO}_{2}$ was measured by pulse oximetry (Nonin 9600, Nonin Medical, Inc., Plymouth, USA) on the right forefinger tip. Ventilation $\left(\dot{\mathrm{V}}_{\mathrm{E}}\right)$ and alveolar gas exchange including endtidal partial pressures for $\mathrm{O}_{2}$ and $\mathrm{CO}_{2}\left(\mathrm{PETO}_{2}\right.$ and $\mathrm{PETCO}_{2}$, respectively) were measured breath-by-breath throughout the test. The inspiratory and expiratory flow and volumes were monitored by a low-deadspace, low-resistance turbine (Triple V, Jaeger Mijnhardt, Bunnik, The Netherlands) connected to a mask (Hans Rudolph Inc., Kansas City, MO). The turbine was calibrated before each test by a 3.00-L syringe (Hans Rudolph Inc.). Inspired and expired gases were sampled continuously at the mouth and the concentrations of $\mathrm{O}_{2}$, $\mathrm{CO}_{2}, \mathrm{~N}_{2}$, and argon were analyzed by mass spectrometry (AMIS 2000, Innovision, Odense, Denmark) after calibration with precision analyzed gas mixtures. The raw data were transferred to a computer where gas delays were determined for each breath to align concentrations with volume data, and to build a profile of each breath. Breath-by-breath alveolar gas exchange was calculated with the AMIS algorithms, which are slightly modified from the original algorithms of Beaver et al. (1981) and interpolated to give second by second values. In this study $\mathrm{PETCO}_{2}$ was used as an index of arterial $\mathrm{CO}_{2}$ pressure instead of direct measurement.

For both pre- and post-expedition testing, acute hypoxic ventilatory chemosensitivity (AHVR) was obtained by calculating the linear regression slope of $\dot{\mathrm{V}}_{\mathrm{E}}$ versus $\mathrm{SpO}_{2}$ $\left(\mathrm{L} \cdot \min ^{-1} \cdot \%^{-1}\right)$ from the beginning of normoxic exercise up to a standardized hypoxic load (4800 $\mathrm{m}$ above sea level) and also to the peak hypoxic load achieved by each participant (normoxic exercise - peak hypoxic exercise). Thus, ventilation was plotted as a function of $\mathrm{SpO}_{2}$ on a second-by-second basis and the slope of the regression line, $\Delta \dot{\mathrm{V}}_{\mathrm{E}} / \Delta \mathrm{SpO}_{2}$, was defined as AHVR during standard walking but increasing hypoxic challenge. This method to determine AHVR during exercise has been used previously by Sato et al. (1996) and Peltonen et al. (2009).

\section{Near-infrared spectroscopy}

Regional cerebral (frontal cortex or FC) and muscle (vastus lateralis or VL) tissue oxygenation profiles were monitored noninvasively by near-infrared-spectroscopy (NIRS) (Oxymon, Artinis Medical Systems, Zetten, the Netherlands), which enabled continuous monitoring of tissue saturation index (TSI) along with relative concentration changes in oxy- $\left(\Delta\left[\mathrm{O}_{2} \mathrm{Hb}\right]\right)$, deoxy- $(\Delta[\mathrm{HHb}])$, and total $(\Delta[\mathrm{tHb}])$ hemoglobin. For both cerebral and muscle measurements, the optodes with three transmitters, operating at wavelengths of 765 and $860 \mathrm{~nm}$, and one receiver were housed in an optically dense plastic holder and attached firmly on the skin using two-sided and one-sided tape. The FC optode was additionally fixed with a headband. The cerebral probe was located over the right frontal cortex, on 
average $\sim 3 \mathrm{~cm}$ above the right eyebrow and $\sim 4.5 \mathrm{~cm}$ lateral from the middle line of the forehead. This site over the prefrontal cortex is assumed to be involved in the higher aspects of motor control and the planning of voluntary movement (Sahyoun et al., 2004). The vastus lateralis was chosen to represent active muscle, as it is a powerful knee-extensor that is activated at several phases of the walking gait cycle (Murray et al., 1984). Muscle optodes were placed on the right vastus lateralis in parallel with the long axis of the muscle, $\sim 14 \mathrm{~cm}$ above the upper edge of the patella and $\sim 4 \mathrm{~cm}$ lateral from the middle line. The inter-optode distances were $40 \mathrm{~mm}$ for vastus lateralis and $45 \mathrm{~mm}$ for frontal cortex but they were changed, if needed, when checking the quality of signals before starting the measurements. Before fixing optodes hair, if existed, was shaved and the skin was wiped. The exact place of all optodes was marked and measured individually during both tests. Adipose tissue thickness from the thigh was measured with skinfold caliper PRE and POST to control effect of subcutaneous adipose tissue on the signal.

The theory of NIRS and details on its use in exercise have been described in detail elsewhere (Boushel et al., 2001). Briefly, the intensity of incident and transmitted light was recorded continuously and, along with the specific extinction coefficients and optical path length, used for on-line estimation and display of concentration changes $(\Delta \mu \mathrm{M})$ from the resting baseline of $\Delta\left[\mathrm{O}_{2} \mathrm{Hb}\right], \Delta[\mathrm{HHb}]$, and total hemoglobin $\Delta[\mathrm{tHb}$. The values used for the differential pathlength factor (DPF) were 5.51 for the leg ( van der Zee et al., 1992; Duncan et al., 1995), and calculated for cerebral tissue as $\mathrm{DPF}=4.99+0.067 \times \mathrm{Age}^{0.814}$ according to the manufacturer's guidelines. The tissue saturation index (TSI, \% $\%\left[\mathrm{O}_{2} \mathrm{Hb}\right] /$ $[\mathrm{tHb}])$ was calculated from the light attenuation slope along the distance from the three emitting points as detected by the sensor in the receiving optode. Data from NIRS were averaged to give values in $1 \mathrm{sec}$ intervals, and time-aligned with gas exchange, heart rate, and $\mathrm{Spo}_{2}$ data. When performing NIRS analyses, the values obtained during exercise-hypoxia were compared with the values of normoxic walking exercise instead of rest because, at the onset of exercise, muscle pumping expels blood from the muscles towards the heart, which is expected to explain the rapid temporary changes on NIRS measurements (DeLorey et al., 2003).

\section{Total hemoglobin mass measurement}

During a visit to the laboratory either a day before or after the exercise-hypoxia test, total hemoglobin mass was assessed using CO rebreathing (COR) as described in detail by Schmidt and Prommer (2005) and modified by Prommer and Schmidt (2007). In brief, after 15-min resting in a sitting position, the subjects were connected to a specially designed closed spirometric system allowing a CO-bolus application, followed by 2 min rebreathing of approximately $3 \mathrm{~L}$ amount of oxygen. The administered amount of $\mathrm{CO}$ in $\mathrm{mL}$ was individually calculated $(\mathrm{mL} \mathrm{CO}=1.0 \mathrm{x}$ body weight $(\mathrm{kg})$ ). During COR, the whole apparatus was checked for $\mathrm{CO}$ leakage with a portable CO-gas analyzer (Dräger Pac 7000, Dräger Safety AG \& Co. KGaA, Lübeck, Germany). This analyzer was also used to calculate the amount of $\mathrm{CO}$ that had not been taken up by the body from the remaining $\mathrm{CO}$ in the spirometer and the residual volume of the lung, as well as from the $\mathrm{CO}$ exhaled after disconnecting the subject from the spirometer, at min 4 after the beginning of the COR period.
Blood samples were drawn from a fingertip immediately before, 6 and $8 \mathrm{~min}$ after the start of the COR period. For $\% \mathrm{HbCO}$ and hemoglobin concentration measurements, blood was drawn into two $100 \mu \mathrm{L}$ preheparinized capillaries (Clinitubes, Radiometer Medical ApS, Copenhagen, Denmark). After the blood drawing, the tubes were closed and mixed with a wire and magnet. Each of the two samples was measured immediately in triplicate by oximetry (OSM3, Radiometer, Copenhagen, Denmark) and the average of the replicates was used for further calculations, as suggested by Alexander et al. (2011) to minimize analyzer error to $<1 \%$. Daily, the OSM3 was calibrated to standard and the quality of measurement was checked by means of three different quality control solutions. tHb-mass, erythrocyte volume, plasma volume and blood volume were calculated by the SpiCO Software 1.0 (Blood tec, Bayreuth, Germany), which was developed and patented by the founders Schmidt and Prommer (2005), and Prommer and Schmidt (2007). The tHb-mass was calculated based on the formula: $\mathrm{tHb}$ mass $(\mathrm{g})=\mathrm{K} \times \mathrm{MCO} \times 100 \times\left((\Delta \% \mathrm{HbCO} \times 1.39)^{-1}\right.$, where $\mathrm{K}$ is ambient barometric pressure $(\mathrm{mmHg}) \times 760^{-1}(\mathrm{mmHg}) \mathrm{x}$ $\left[1+\left(0.003661 \times\right.\right.$ ambient temperature $\left.\left.{ }^{\circ} \mathrm{K}\right)\right], \mathrm{MCO}$ is the volume of $\mathrm{CO}(\mathrm{mL})$ applied to the system minus the sum of $\mathrm{CO}$ volume remaining in the spirometer and the volume that was exhaled from minute 2-8 (the $\mathrm{CO}$ volume not bound to hemoglobin), $\Delta \% \mathrm{HbCO}$ is the difference between the initial $\% \mathrm{HbCO}$ (mean \% HbCO of two initial blood samples) and maximal \% $\mathrm{HbCO}$ (average $\% \mathrm{HbCO}$ of blood samples at minutes 6 and 8 after starting the COR), and $1.39\left(\mathrm{~mL} \mathrm{~g}^{-1}\right)$ is Hüfners number as $1.39 \mathrm{~mL} \mathrm{CO}$ bind to $1 \mathrm{~g} \mathrm{Hb}$.

The software program SpiCO corrects for the loss of $\mathrm{CO}$ from hemoglobin to myoglobin according to the findings of Schmidt and Prommer (2005) and by Prommer and Schmidt (2007) by $0.3 \%$ of administered CO per minute. The calculation of $\mathrm{EV}=\left(644 \times \mathrm{Hct}(\%) \times[\mathrm{Hb}]^{-1}(\mathrm{~g} / \mathrm{L})\right) \times \mathrm{tHb}$-mass (mmol) is based on the equations 1-3 presented by Burge and Skinner (1995). The typical error (\% TE) of the tHb-mass measurement in our laboratory obtained by duplicate tests is $1.7 \%$ (95\% confidence limit $1.3 \%-2.4 \%$ ) for relative tHbmass and $2.0 \%$ (95\% CL $1.5 \%-2.8 \%$ ) for absolute tHb-mass (Koponen et al., 2013). This is similar to Schmidt and Prommer (2005) who reported the reliability of the tHb-mass measurement as $1.7 \%$ TE (95\% CL 3.3\%).

\section{Statistical analyses}

Exercise-hypoxia tolerance, thigh skinfold thickness, hematological responses (tHb-mass; erythrocyte, plasma, and blood volumes), and AHVR (from 0-4800 $\mathrm{m}$ and from $0 \mathrm{~m}$, peak hypoxia) were compared pre/post-expedition using a paired $t$-test. For the exercise-hypoxia test, the mean values of the last $30 \mathrm{sec}$ of each exercise-hypoxic step were chosen for statistical analysis. Cardiorespiratory variables $\left(\dot{\mathrm{V}}_{\mathrm{E}}\right.$, heart rate), arterial oxygen saturation, along with cerebral and muscle oxygenation variables over the course of exercisehypoxia were compared using a one-way repeated measures ANOVA with Holm-Sidak post-hoc analysis. Comparisons between PRE and POST at a given altitude and at peak altitude was performed by paired $t$-test. The simulated altitudes of 0-4800 $\mathrm{m}$ were used as the common levels of comparison, as $4800 \mathrm{~m}$ represented the highest hypoxic level tolerated by all participants both PRE and POST. Relationships between cerebral and vastus lateralis TSI versus AHVR were tested by 
Pearson product correlation. All data were checked for normal distribution and statistical analyses were performed using PASW Statistics 18.0 software (SPSS Inc., Chicago, IL, USA). Results are expressed as means \pm SD unless otherwise indicated. A $p$ value of $<0.05$ was considered statistically significant.

\section{Results}

\section{Hypoxic exercise and ventilatory response}

During PRE, all participants completed 3 min of walking at $3500 \mathrm{~m}$ and were able to exercise at $4800 \mathrm{~m}$ for at least $1 \mathrm{~min}$. Hypoxic-exercise tolerance improved in POST, with all participants completing exercise at $5200 \mathrm{~m}$ and able to walk at $5800 \mathrm{~m}$ for at least 1.5 minutes. The progressive hypoxia was tolerated for 11:32 $\pm 3: 57$ (min:sec) in PRE and $16: 30 \pm 2: 09$ in POST $(p<0.01)$, with increased exercise time in 8 of 9 participants. Ventilatory and arterial saturation data are presented in Figure 1. Ventilation during both PRE $(\mathrm{df}=4, \mathrm{~F}=33.3, p<0.001)$ and POST $(\mathrm{df}=6, \mathrm{~F}=39.6$, $p<0.001)$ exercise-hypoxic exposure progressively increased throughout each exercise-hypoxic stage from $0 \mathrm{~m}$ to peak hypoxic stage. Between $0 \mathrm{~m}$ to $4800 \mathrm{~m}, \dot{\mathrm{V}}_{\mathrm{E}}$ was higher POST $(p<0.05)$ at $3500 \mathrm{~m}$. Compared to $0 \mathrm{~m}$ exercise, $\mathrm{PETCO}_{2}$ was lower during PRE $(\mathrm{df}=4, \mathrm{~F}=39.3, p<0.001)$ from $3500 \mathrm{~m}$ through to peak hypoxic exposure and in POST $(\mathrm{df}=6, \mathrm{~F}=142.0, p<0.001)$ at all exercise-hypoxic stages. $\mathrm{PETCO}_{2}$ was lower during POST than PRE at rest, $2400 \mathrm{~m}$, and $3500 \mathrm{~m} . \mathrm{SpO}_{2}$ steadily decreased over the course of each exercise-hypoxic stage in both PRE ( $\mathrm{df}=4, \mathrm{~F}=93.6$, $p<0.001)$ and POST $(\mathrm{df}=6, \mathrm{~F}=104.0, p<0.001)$ from $0 \mathrm{~m}$ exercise through to peak exercise-hypoxic stage; between PRE and POST, $\mathrm{Spo}_{2}$ were similar up to $3500 \mathrm{~m}$, but was maintained at a higher level at $4800 \mathrm{~m}(p<0.001)$ during POST. $\mathrm{SpO}_{2}$ at peak exposure were similar, at $65 \pm 4$ and $64 \pm 3 \%$ for peak exercise-hypoxia in PRE and POST, respectively, but in POST this level was achieved at greater simulated altitude. Acute hypoxic ventilatory response, defined as the increase in $\dot{\mathrm{V}}_{\mathrm{E}}$ per percentage decrease in arterial saturation $\left(\mathrm{SpO}_{2}\right)$ from $0 \mathrm{~m}$ exercise to $4800 \mathrm{~m}$ hypoxia, increased sharply following chronic hypoxia in 7 of 9 participants, with 1 unchanged and 1 decreasing (Table 1).

\section{Cerebral and muscle oxygenation}

As compared to the normoxic walking, cerebral oxygenation was reduced over the course of each exercise-hypoxic stage in both the PRE and POST trials (Fig. 2), as indicated by progressively decreasing TSI (PRE: $\mathrm{df}=4, \mathrm{~F}=86.5$, $p<0.001$; POST: $\mathrm{df}=6, \mathrm{~F}=65.3, p<0.001)$ and $\Delta\left[\mathrm{O}_{2} \mathrm{Hb}\right]$ (PRE: $\mathrm{df}=4, \mathrm{~F}=69.8, p<0.001$; POST: $\mathrm{df}=6, \mathrm{~F}=104.6$, $p<0.001$ ), and increasing $\Delta[\mathrm{HHb}](\mathrm{PRE}: \mathrm{df}=4, \mathrm{~F}=57.5$, $p<0.001$; POST: $\mathrm{df}=6, \mathrm{~F}=68.5, p<0.001)$. Comparing between PRE and POST trials, the levels of $\Delta[\mathrm{HHb}]$ were significantly lower during POST at 2400,3500 , and $4800 \mathrm{~m}$ $(p<0.05$ to 0.01$)$.

Tissue saturation index at the vastus lateralis were similar to $0 \mathrm{~m}$ exercise at both 2400 and $3500 \mathrm{~m}$, but decreased from $4800 \mathrm{~m}$ and beyond in both PRE $(\mathrm{df}=4, \mathrm{~F}=23.0, p<0.001)$ and POST ( $\mathrm{df}=6, \mathrm{~F}=43.4, p<0.001)$ testing (Fig. 3). In POST compared to PRE, TSI was similar up to $4800 \mathrm{~m}$, but was significantly lower during peak exercise-hypoxia $(p<0.05)$; the TSI slope (i.e., the rate of deoxygenation from $0 \mathrm{~m}$ to peak
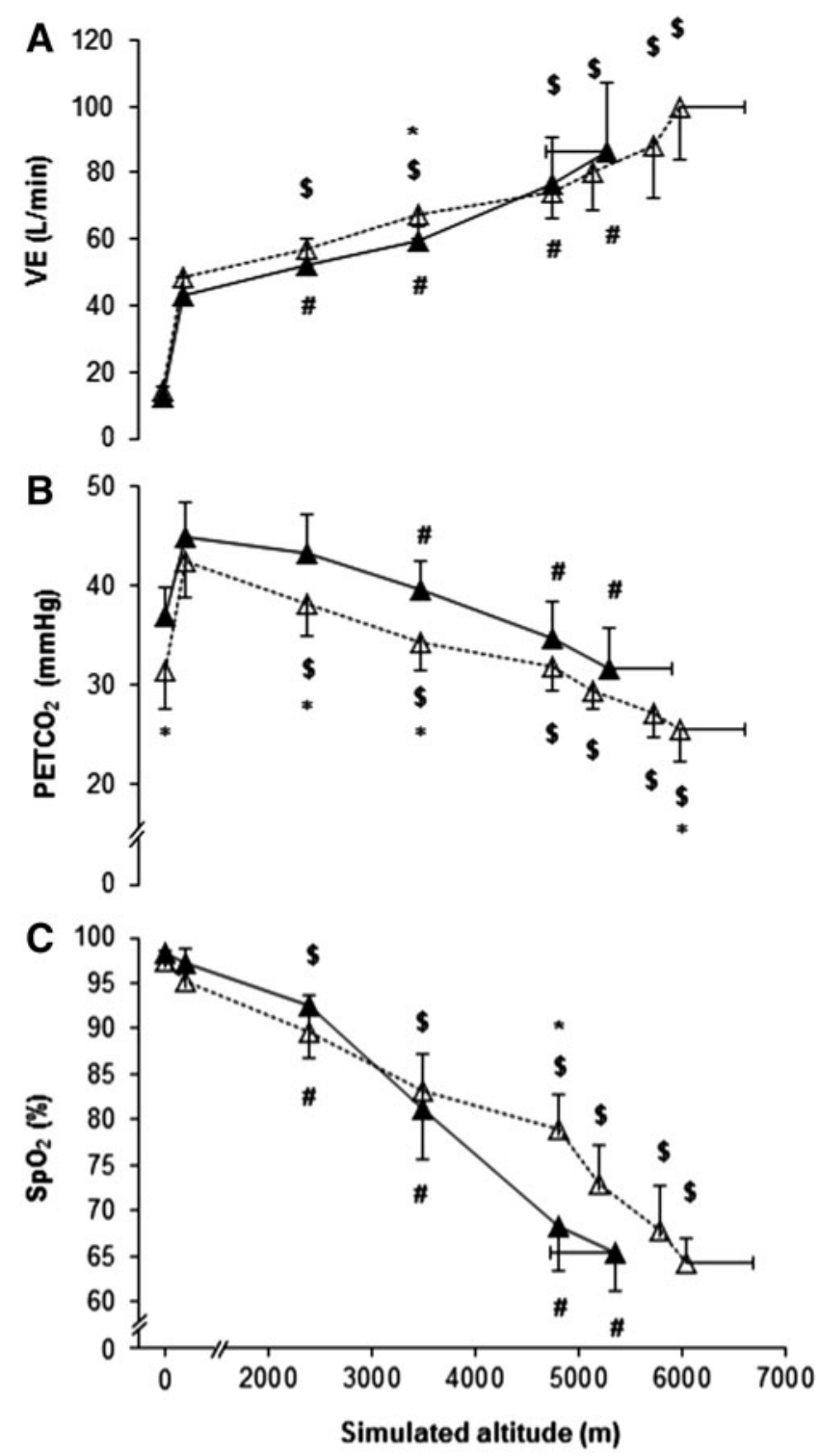

FIG. 1. (A) Ventilation; (B) end-tidal $\mathrm{CO}_{2}$; and (C) arterial oxygen saturation responses to exercise-hypoxia during $\operatorname{PRE}(\boldsymbol{\Delta})$ and POST $(\triangle)$. * Significantly different from PRE $(p<0.05)$. "Significantly different from normoxic walking in PRE $(p<0.05)$. ${ }^{\$}$ Significantly different from normoxic walking in POST $(p<0.05)$. In order to improve the clarity of the figure, the $\mathrm{x}$-value of baseline walking is artificially raised to $200 \mathrm{~m}$.

hypoxia) was significantly greater in POST than in PRE $(-0.63$ and $-0.46 \% \cdot \%^{-1}$, respectively). Leg $\Delta[\mathrm{HHb}](\mathrm{PRE}: \mathrm{df}=4$, $\mathrm{F}=23.3, p<0.001 ;$ POST: $\mathrm{df}=6, \mathrm{~F}=67.8, p<0.001)$, and $\Delta[\mathrm{tHb}] \quad(\mathrm{PRE}: \mathrm{df}=4, \mathrm{~F}=25.5, p<0.001 ; \quad$ POST: $\mathrm{df}=6$, $\mathrm{F}=130.6, p<0.001)$ increased in both tests, with no differences in $\Delta[\mathrm{HHb}]$ or in $\Delta[\mathrm{tHb}]$ between PRE and POST up to $4800 \mathrm{~m}$ or at peak exercise-hypoxia. The $\Delta[\mathrm{HHb}]$ slope was greater in POST than in PRE $\left(0.429\right.$ and $0.279 \mu \mathrm{M} \cdot \%^{-1}$, respectively, $p<0.05)$. In PRE, $\Delta\left[\mathrm{O}_{2} \mathrm{Hb}\right]$ remained at normoxic walking levels during first two hypoxic steps and started to decrease at $4800 \mathrm{~m}(\mathrm{df}=4, \mathrm{~F}=6.5, p<0.001)$. In POST, $\Delta\left[\mathrm{O}_{2} \mathrm{Hb}\right]$ was initially steady, then decreased to significantly lower level than at $0 \mathrm{~m}$ exercise at $5800 \mathrm{~m}$ and peak exercise-hypoxia $(\mathrm{df}=6$, $\mathrm{F}=16.4, p<0.001)$. There were no differences in leg $\Delta\left[\mathrm{O}_{2} \mathrm{Hb}\right]$ 
Table 1. Body Mass, Total Hemoglobin Mass, Erythrocyte Volume, and Ventilatory Chemosensitivity Responses PRe- and Post-Expedition

\begin{tabular}{|c|c|c|c|c|c|c|c|c|c|c|c|c|c|c|}
\hline & \multicolumn{2}{|c|}{$\begin{array}{c}\text { Body } \\
\text { mass (kg) }\end{array}$} & \multicolumn{2}{|c|}{$\begin{array}{c}\text { Plasma } \\
\text { volume }(m L)\end{array}$} & \multicolumn{2}{|c|}{$\begin{array}{c}\text { Total } \\
\text { blood volume }(\mathrm{mL})\end{array}$} & \multicolumn{2}{|c|}{$\left(g \cdot d L^{-1}\right)$} & \multicolumn{2}{|c|}{$\begin{array}{c}t H b- \\
\operatorname{mass}(g)\end{array}$} & \multicolumn{2}{|c|}{$\begin{array}{c}E V \\
(m L)\end{array}$} & \multicolumn{2}{|c|}{$\begin{array}{c}A H V R(0-4800 \mathrm{~m}) \\
\left(L \cdot \min ^{-1} \cdot \%^{-1}\right)\end{array}$} \\
\hline & $P R E$ & POST & $P R E$ & POST & $P R E$ & POST & $P R E$ & POST & $P R E$ & POST & $P R E$ & POST & $P R E$ & POST \\
\hline 1 & 81.3 & 79.6 & 4879 & 4908 & 8294 & 8132 & 14.5 & 14.5 & 1095 & 1074 & 3415 & 3224 & 1.31 & 1.78 \\
\hline 2 & 86.7 & 83.3 & 5743 & 4786 & 9454 & 33 & 14.4 & 15.1 & 1241 & 1113 & 3712 & 3298 & 1.11 & 2.35 \\
\hline 3 & 68.7 & 67.3 & 3422 & 2719 & 5585 & 525 & 13.9 & 17.0 & 706 & 811 & 2163 & 2533 & 1.00 & 1.03 \\
\hline 4 & 71.5 & 71.6 & 4369 & 3929 & 7147 & 6859 & 14.2 & 15.2 & 927 & 949 & 2779 & 2929 & 0.90 & 1.26 \\
\hline 5 & 70.1 & 68.4 & 3668 & 3853 & 6234 & 6699 & 14.3 & 14.7 & 813 & 895 & 2567 & 2846 & 1.69 & 1.83 \\
\hline 6 & 85.0 & 80.9 & 4925 & 4710 & 8213 & 8188 & 13.7 & 14.9 & 1025 & 1107 & 3287 & 3479 & 0.83 & 1.66 \\
\hline 7 & 88.2 & 84.0 & 4562 & 3983 & 7 & 71 & 14.4 & 16.0 & 992 & 1046 & 2997 & 3200 & & 1.60 \\
\hline 8 & 97.2 & 88.8 & 4576 & 4199 & 7297 & 8028 & 14.9 & 16.7 & 987 & 1220 & 2921 & 3829 & 1.73 & 1.78 \\
\hline 9 & 80.2 & 78.6 & 4600 & 4229 & 7574 & 7284 & 14.4 & 15.3 & 994 & 1014 & 2974 & 3055 & 1.49 & 1.41 \\
\hline Mean & 81.0 & 78.1 & 4505 & 4146 & 7484 & 7301 & 14.3 & 15.5 & 975 & 1025 & 2979 & 3155 & 1.25 & 1.63 \\
\hline SD & & 7.4 & 686 & 663 & 1140 & 961 & & 0.9 & 154 & 124 & 461 & 376 & 0.33 & 0.38 \\
\hline $\mathrm{P}$ value & \multicolumn{2}{|c|}{$0.01 *$} & \multicolumn{2}{|c|}{$0.02 *$} & \multicolumn{2}{|c|}{0.38} & \multicolumn{2}{|c|}{$0.01 *$} & \multicolumn{2}{|c|}{0.17} & \multicolumn{2}{|c|}{0.19} & $0.03 *$ & \\
\hline
\end{tabular}

AHVR, acute hyperventilatory response; EV, erythrocyte volume; $[\mathrm{Hb}]$, hemoglobin concentration; tHb-mass, total hemoglobin mass. *Significantly different PRE to POST.

between the PRE and POST up to $4800 \mathrm{~m}$ or at peak exercisehypoxia. No significant relationship was evident in either the cerebral or vastus lateralis sites between the magnitude of the AHVR and the slope for TSI with decreasing $\mathrm{SpO}_{2}$ during either PRE or POST.

\section{Red blood cell responses}

The expedition elicited no significant change in total blood volume along with a plasma volume decrease post-expedition
(Table 1). Hemoglobin concentration significantly increased post-expedition $\left(14.3 \pm 0.4 \mathrm{PRE}\right.$ to $15.5 \pm 0.9 \mathrm{~g} \cdot \mathrm{dL}^{-1}$ POST, $p=0.01$ ), but absolute total hemoglobin masses were similar $(p=0.17)$ at $975 \pm 154 \mathrm{~g}(\mathrm{PRE})$ and $1025 \pm 124 \mathrm{~g}$ (POST). A large inter-individual variability existed in the direction and magnitude of the tHb-mass changes, ranging from $-14.5 \%$ to $20.2 \%$, with seven participants increasing and two decreasing post-expedition. Erythrocyte volume also demonstrated a similar pattern of no overall changes post-expedition $(p=0.19)$ and wide inter-individual variability, ranging from $-10.3 \%$ to $31 \%$.
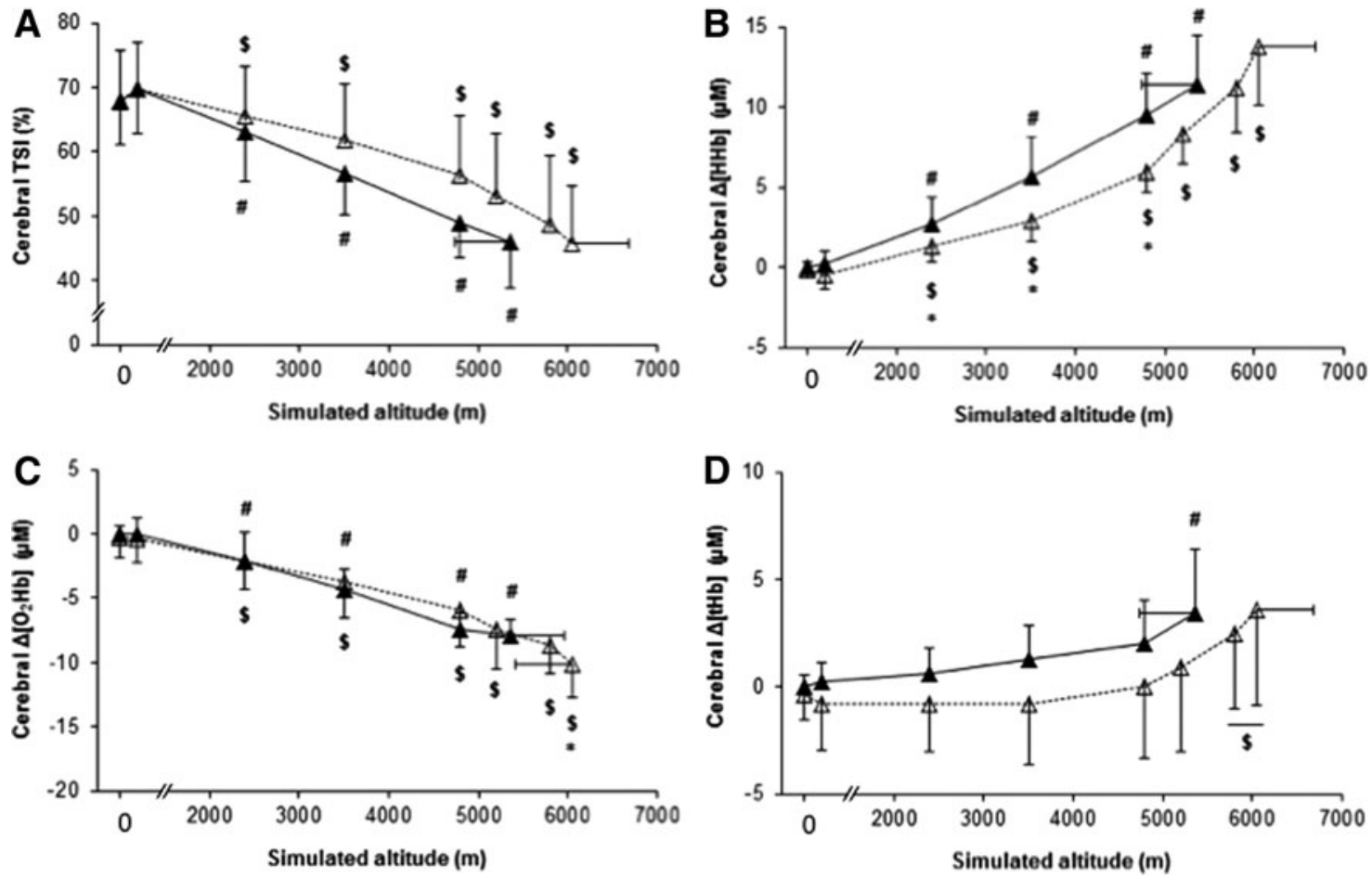

FIG. 2. Frontal cortex oxygenation responses to exercise-hypoxia during PRE $(\boldsymbol{\Delta})$ and POST $(\triangle)$. *Significantly different from PRE $(p<0.05)$. "Significantly different from normoxic walking in PRE $(p<0.05)$. Significantly different from normoxic walking in POST $(p<0.05)$. In order to improve the clarity of the figure, the $\mathrm{x}$-value of baseline walking is artificially raised to $200 \mathrm{~m}$. 

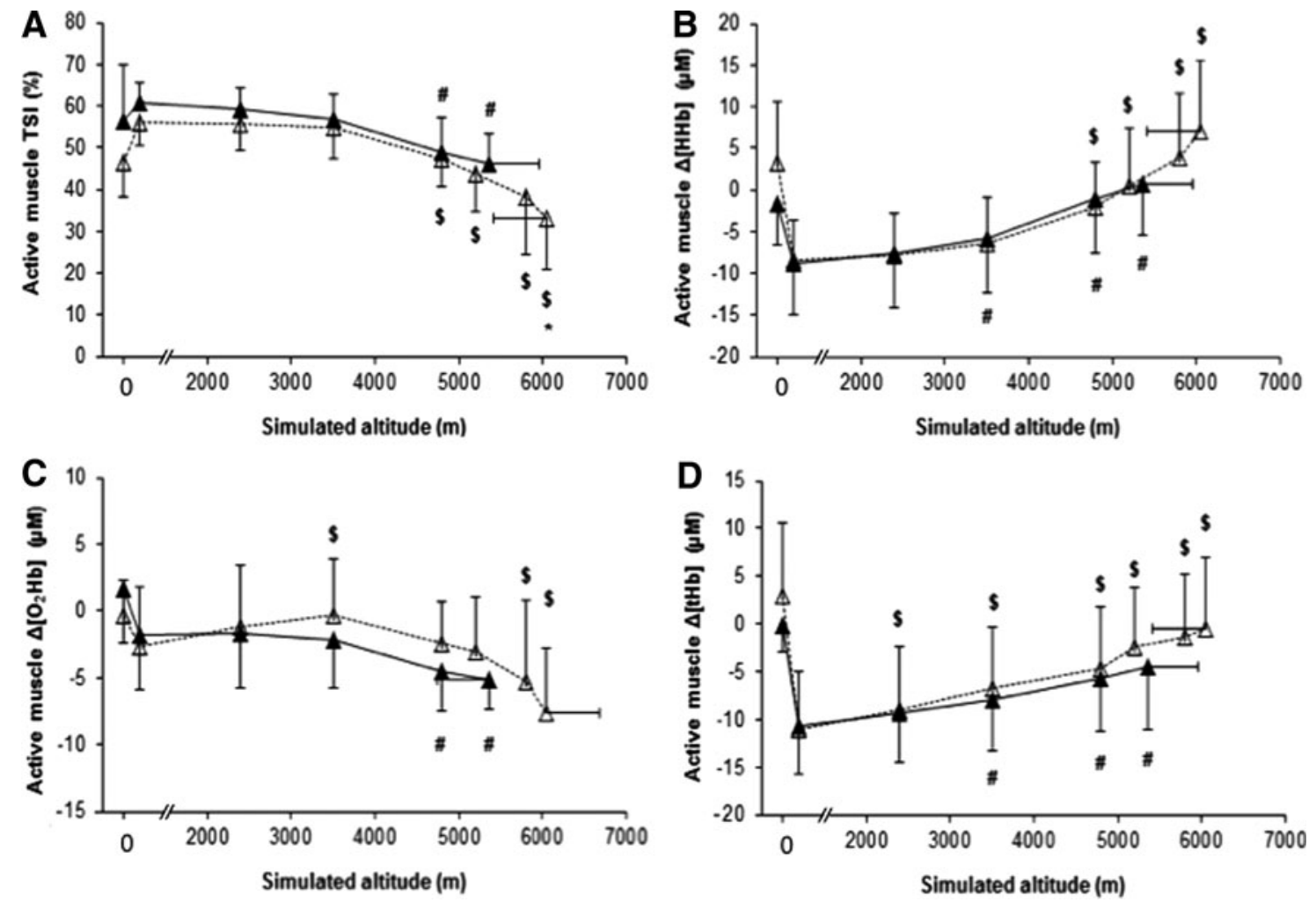

FIG. 3. Vastus lateralis oxygenation responses to exercise-hypoxia during PRE ( $\Delta)$ and POST $(\triangle)$ ). $*$ Significantly different from PRE $(p<0.05)$. ${ }^{\#}$ Significantly different from normoxic walking in PRE $(p<0.05)$. ${ }^{\$}$ Significantly different from normoxic walking in POST $(p<0.05)$. In order to improve the clarity of the figure, the $\mathrm{x}$-value of baseline walking is artificially raised to $200 \mathrm{~m}$.

\section{Discussion}

To our knowledge, this is the first study on the effects of an extended mountaineering expedition on the combined ventilatory, arterial saturation, cerebral and muscle oxygenation, and total hemoglobin mass responses. We utilized a constant exercise with increasing levels of poikilocapnic hypoxia and investigated the potential and mechanisms for adaptation by performing the test before and following a self-supported Mount Everest expedition. A greater tolerance to an acute exercise-hypoxia challenge existed post-expedition, and acute hypoxic ventilatory response was enhanced while arterial oxygen saturation was maintained at higher levels postexpedition. Cerebral oxygenation was better maintained post-expedition, yet the degree of AHVR either before or following the expedition was not associated with either cerebral or active muscle oxygenation. Total hemoglobin mass tended towards increasing post-expedition, but high interindividual variability precluded any group significance.

Hyperventilation is a common response to acute and chronic hypoxia, and our data demonstrated increasing $\dot{\mathrm{V}}_{\mathrm{E}}$ over the acute exercise-hypoxia challenge both pre- and postexpedition (Savourey et al., 1996). As our protocol maintained a constant exercise with step increases in hypoxia, this supports the idea that the hyperventilation was driven by the poikilocapnic hypoxia stimulus itself rather than any exercise-induced changes in metabolic demands or afferent (e.g., mechanoreceptor) feedback seen in prior studies utilizing a single hypoxic stage with a graded exercise test (Subudhi et al., 2007; Peltonen et al., 2009). In general, hy- perventilation drives down $\mathrm{PETCO}_{2}$ and leads to a higher $\mathrm{pH}$ and an increased hemoglobin binding affinity for oxygen, thus potentially helping to preserve arterial saturation overall. The acute hypoxic ventilatory response, calculated as the increase in $\dot{\mathrm{V}}_{\mathrm{E}}$ for a set decrease in $\mathrm{Spo}_{2}$ from $0-4,800 \mathrm{~m}$ (Table 1), was increased by $30 \%$ post-expedition. This suggests that ventilatory chemosensitivity was enhanced over the expedition, possibly contributing to the maintenance of arterial saturation. A protective effect in $\mathrm{Spo}_{2}$ was evident at $4800 \mathrm{~m}$ and beyond, with a rightward shift of approximately $1000 \mathrm{~m}$ for an equivalent arterial oxygen saturation as during pre-expedition (Fig. 1). While lower $\mathrm{SpO}_{2}$ values of $60 \%$ or less have been reported in the field during moderate exercise after acclimatization at $5800 \mathrm{~m}$ (West et al., 1962), more recent field data on expedition climbers exercising at $5300 \mathrm{~m}$ reported $\mathrm{SpO}_{2}$ values $>70 \%$ (Karinen et al., 2010), similar to our current data. Overall, our data suggest that chronic hypoxic acclimatization enhanced ventilatory chemosensitivity, but that these adaptations only became expressed in preserving higher arterial saturation once the body reached a moderate threshold of exercise and/or hypoxic stress.

The actual level of oxygen availability at the brain or muscle tissues may be altered by altitude acclimatization. The possible effects of chronic hypoxia on cerebral blood flow (Ainslie et al., 2007; Lucas et al., 2010) and subsequently on cerebral oxygenation, were beyond the scope of the present study. Cerebral oxygenation in our study, as measured using NIRS, changed similarly during exercisehypoxia both pre- and post-expedition, with progressively decreasing TSI and $\Delta\left[\mathrm{O}_{2} \mathrm{Hb}\right]$ along with an increasing 
$\Delta[\mathrm{HHb}]$. No significant differences occurred between preand post-expedition trials in TSI or in $\Delta\left[\mathrm{O}_{2} \mathrm{Hb}\right]$, though a trend towards improved cerebral TSI existed in POST. Vastus lateralis skinfold thickness did not differ significantly PRE and POST $(8.1 \pm 2.6$ and $5.8 \pm 3.2 \mathrm{~mm}, p=0.09)$. This lack of difference in skinfold thickness, along with the NIRS data being similar PRE/POST at the $0 \mathrm{~m}$ exercise, supports the idea that any changes in NIRS during exercise-hypoxia probably reflect acclimatization rather than skinfold thickness differences. Similar to cerebral values, muscle oxygenation pre-expedition gradually decreased over the course of exercise-hypoxia, with progressive decreases in TSI and increasing $\Delta[\mathrm{HHb}]$ as the level of hypoxia increased. The expedition did not appear to impact muscle oxygenation, as muscle oxygenation continued to decrease with further levels of hypoxia in both PRE and POST, with similar values and patterns for TSI, $\Delta\left[\mathrm{O}_{2} \mathrm{Hb}\right]$, $\Delta[\mathrm{HHb}]$, and $\Delta[\mathrm{tHb}]$ up to a simulated $4800 \mathrm{~m}$. Therefore, any differences post-expedition appear primarily due to the greater level of exercise-hypoxia during POST rather than any specific acclimatization changes to muscle oxygenation.

A strong HVR has been proposed as a predictor for altitude performance (Schoene et al., 1984), with reports of higher HVR in elite climbers compared to sedentary controls and endurance athletes (Schoene, 1982). However, the actual mechanism for any HVR protection remains unknown, and some argue that a strong HVR may form a negative response due to diminishing ventilatory reserve (Bernardi et al., 2006). Ainslie and Poulin (2004) reported that, across individuals, a higher AHVR during acute poikilocapnic hypoxia was associated with a decrease in the acute hypoxic cerebral blood flow response, but propose that this may be due to the hyperventilation already inducing a hypocapnic-induced cerebral vasoconstriction and dampening the possibility for further responsiveness. In our study, despite a wide interindividual variability in AHVR both before and following the expedition, no significant relationship existed between AHVR and the slope for cerebral or vastus lateralis TSI changes, suggesting that neither a higher nor lower ventilatory response to hypoxia impacted the actual oxygenation at the brain or active musculature.

Absolute total hemoglobin mass exhibited a nonsignificant trend towards increasing post-expedition, but the wide range of responses may have dampened overall group effects and highlights the wide inter-individual variability in response to altitude. Seven climbers increased their tHb-mass (range $2.0 \%-23.7 \%)$, but a reduction $(1.9 \%-10.3 \%$ ) was seen in two climbers. These changes are greater than the $\mathrm{CV}$ of our COR method, suggesting that these results are most likely real and not a measurement error. Also, our testing window of 9-15 days post-expedition was similar to the 14 days reported by Prommer et al. (2010) for maintenance of elevated tHb-mass upon descent to sea level.

Several possibilities may explain the lack of tHb-mass elevation or its wide variability. The expedition being selfsupported would have increased the overall physical stress, and this may have affected the ability to produce red cells and hemoglobin synthesis. Our data are also consistent with equivocal findings of hematological responses to chronic moderate altitude exposure, with both 'responders' and 'non-responder' in [EPO] and running performance following a 'live-high-trainlow' altitude training regimen (Chapman et al., 1998) — with only the 'responders' exhibiting an increased total red cell volume. Variability is also evident when actually measuring total hemoglobin mass at moderate altitude. Siebenmann et al. (2012) exposed athletes to either live-high-trainlow for $16 \mathrm{~h}$ daily at a simulated $3000 \mathrm{~m}$ or else a blinded, placebo nonhypoxic exposure and training for 4 weeks. Notably, high inter-individual variability in tHb-mass was reported in the live-high-train-low group, with five of ten exhibiting increases but three significantly decreasing tHbmass. In a review of the effects of endurance training at altitude, Saunders et al. (2009a) also concluded a general trend of progressively increasing tHb-mass with exposure time to hypoxia; however, in all modes of training (e.g., live-hightrain-high and live-high-train-low), a wide inter-individual variation in responses existed. Our data suggest a similar wide variability in response also prevails at high and extreme altitudes in climbers, at least during self-supported expeditions. The genetic bases for a phenotypic dichotomy remain open to debate, as an examination of eight different genes involved in erythropoietin regulation did not produce a significant association with erythropoietin response to $24 \mathrm{~h}$ of hypoxia (Jedlickova et al., 2003).

\section{Limitations}

As with any field study, research design and expedition imperatives must be balanced. Unlike laboratory studies, sample size was constrained to the nine expedition members and could not be simply increased to strengthen statistical power. This may have especially influenced our ability to truly discern the effects of such prolonged expeditions on tHb-mass. The participants were all experienced climbers performing a particularly strenuous self-supported climb, so the results may have been impacted by the heavy exercise and thus not directly generalizable to the normal population of altitude trekkers or guided climbers. While all participants were members of the same expedition, it is recognized that the actual level of exercise, nutrition, and hypoxia exposure was not controlled across the team members. The study design does not completely eliminate the possibility that the prolonged hypoxic tolerance post-expedition were due to improvements in overall fitness or in specific adaptation to the physical demands of mountaineering. A maximal aerobic fitness test was not performed on the climbers post-expedition, as scheduling was prioritized towards a timely testing of the exercise-hypoxic protocol. The exercise-hypoxia exposure had graded hypoxia being the primary stressor, with exercise workload remaining constant. Tolerance time greatly increased in 8 out of 9 participants, which we assume to be due to physiological mechanisms, and not learning effects, as all participants were familiar with exercise testing in laboratory settings from their previous expeditions. Finally, it is possible that de-acclimatization was already occurring during the inevitable delay between the climb's completion and getting the participants back to Finland and post-expedition testing. While Heinicke et al. (2005) reported that tHb-mass returned to baseline values 16 days in elite biathletes following an altitude training camp (2050 m), Prommer et al. (2010) found that, while $\mathrm{tHb}$-mass in elite Kenyan runners eventually decreased upon moving to sea level, this decrease was not evident over the initial 14 days of descent.

\section{Conclusions}

This study investigated the physiological adaptations to a self-supported Everest expedition, featuring both chronic 
hypobaric hypoxia and heavy exercise. The primary finding was that tolerance to progressive hypoxia during steady-state exercise improved post-expedition. In exploring the mechanisms for this improved tolerance, we conclude that, following chronic hypobaric hypoxic acclimatization: 1) ventilatory chemosensitivity to changes in arterial saturation was significantly elevated; 2) arterial oxygenation levels were higher, but only at simulated altitudes $4800 \mathrm{~m}$ and beyond; 3) a lower level of cerebral deoxygenation was observed post-expedition, suggesting less of a mismatching in the ratio between cerebral oxygen delivery and utilization, while active muscle oxygenation did not change to a major degree; and 4) total hemoglobin mass showed tendencies for an overall increase but also great inter-individual variability. The magnitude of acute hypoxic ventilatory response did not influence the response of cerebral or active muscle oxygenation to acute exercise-hypoxia.

\section{Acknowledgments}

The authors are indebted to the participants for their perseverance and spirit throughout the experiment and expedition. This study was partly funded by Tekes - the Finnish Funding Agency for Technology and Innovation (40043/07), and Ministry of Education and Culture (Finland). S.S. Cheung was supported by a Canada Research Chair.

\section{Author Disclosure Statement}

The authors declare that they have no competing financial interests.

\section{References}

Ainslie PN, Barach A, Murrell C, Hamlin M, Hellemans J, and Ogoh S. (2007). Alterations in cerebral autoregulation and cerebral blood flow velocity during acute hypoxia: Rest and exercise. Am J Physiol: Heart Circ Physiol 292:H976H983.

Ainslie PN, Hamlin M, Hellemans J, Rasmussen P, and Ogoh S. (2008). Cerebral hypoperfusion during hypoxic exercise following two different hypoxic exposures: Independence from changes in dynamic autoregulation and reactivity. Am J Physiol 295:R1613-R1622.

Ainslie PN, and Poulin MJ. (2004). Ventilatory, cerebrovascular, and cardiovascular interactions in acute hypoxia: Regulation by carbon dioxide. J Appl Physiol 97:149-159.

Alexander AC, Garvican LA, Burge CM, Clark SA, Plowman JS, and Gore CJ. (2011). Standardising analysis of carbon monoxide rebreathing for application in anti-doping. J Sci Med Sport 14:100-105.

Beaver WL, Lamarra N, and Wasserman K. (1981). Breath-bybreath measurement of true alveolar gas exchange. J Appl Physiol 51:1662-1675.

Bernardi L, Schneider A, Pomidori L, Paolucci E, and Cogo A. (2006). Hypoxic ventilatory response in successful extreme altitude climbers. Eur Respir J 27:165-171.

Billaut F, Davis JM, Smith KJ, Marino FE, and Noakes TD. (2010). Cerebral oxygenation decreases but does not impair performance during self-paced, strenuous exercise. Acta Physiol (Oxf) 198:477-486.

Boushel R, Langberg H, Olesen J, Gonzales-Alonzo J, Bulow J, and Kjaer M. (2001). Monitoring tissue oxygen availability with near infrared spectroscopy (NIRS) in health and disease. Scand J Med Sci Sports 11:213-222.
Burge CM, and Skinner SL. (1995). Determination of hemoglobin mass and blood volume with CO: Evaluation and application of a method. J Appl Physiol 79:623-631.

Chapman RF, Stray-Gundersen J, and Levine BD. (1998). Individual variation in response to altitude training. $J$ Appl Physiol 85:1448-1456.

DeLorey DS, Kowalchuk JM, and Paterson DH. (2003). Relationship between pulmonary $\mathrm{O}_{2}$ uptake kinetics and muscle deoxygenation during moderate-intensity exercise. J Appl Physiol 95:113-120.

Duncan A, Meek JH, Clemence M, Elwell CE, Tyszczuk L, Cope M, and Delpy DT. (1995). Optical pathlength measurements on adult head, calf and forearm and the head of the newborn infant using phase resolved optical spectroscopy. Phys Med Biol 40:295-304.

Fulco CS, Beidleman BA, and Muza SR. (2013). Effectiveness of preacclimatization strategies for high-altitude exposure. Exerc Sport Sci Rev 41:55-63.

Fulco CS, Muza SR, Beidleman BA, Demes R, Staab JE, Jones JE, and Cymerman A. (2011). Effect of repeated normobaric hypoxia exposures during sleep on acute mountain sickness, exercise performance, and sleep during exposure to terrestrial altitude. Am J Physiol Regul Integr Comp Physiol 300:R428R436.

Gore CJ, Sharpe K, Garvican-Lewis LA, Saunders PU, Humberstone CE, Robertson EY, Wachsmuth NB, Clark SA, McLean BD, and Friedmann-Bette B. (2013). Altitude training and haemoglobin mass from the optimised carbon monoxide rebreathing method determined by a meta-analysis. Br J Sports Med 47:i31-i39.

Gunga HC, Kirsch KA, Roecker L, Kohlberg E, Tiedemann J, Steinach M, and Schobersberger W. (2007). Erythropoietin regulations in humans under different environmental and experimental conditions. Respir Physiol Neurobiol 158:287297.

Heinicke K, Heinicke I, Schmidt W, and Wolfarth B. (2005). A three-week traditional altitude training increases hemoglobin mass and red cell volume in elite biathlon athletes. Int $\mathrm{J}$ Sports Med 26:350-355.

Jedlickova K, Stockton DW, Chen H, Stray-Gundersen J, Witkowski S, Ri-Li G, Jelinek J, Levine BD, and Prchal JT. (2003). Search for genetic determinants of individual variability of the erythropoietin response to high altitude. Blood Cells Mol Dis 31:175-182.

Karinen HM, Peltonen JE, Kahonen M, and Tikkanen HO. (2010). Prediction of acute mountain sickness by monitoring arterial oxygen saturation during ascent. High Alt Med Biol 11:325-332.

Karinen H, Peltonen J, and Tikkanen H. (2008). Prevalence of acute mountain sickness among Finnish trekkers on Mount Kilimanjaro, Tanzania: An observational study. High Alt Med Biol 9:301-306.

Kolb JC, Ainslie PN, Ide K, and Poulin MJ. (2004). Protocol to measure acute cerebrovascular and ventilatory responses to isocapnic hypoxia in humans. Respir Physiol Neurobiol 141:191-199.

Koponen AS, Peltonen JE, Päivinen MK, Aho JM, Hägglund HJ, Uusitalo AL, Lindholm HJ, and Tikkanen HO. (2013). Low total haemoglobin mass, blood volume and aerobic capacity in men with type 1 diabetes. Eur J Appl Physiol 113:1181-1188.

Lucas SJ, Burgess KR, Thomas KN, Donnelly J, Peebles KC, Lucas RA, Fan JL, Basnyat R, Cotter JD, and Ainslie PN. (2010). Alterations in cerebral blood flow and cerebrovascular reactivity during 14 days at 5050 m. J Physiol 589:741-753. 
Masuyama S, Kimura H, Sugita T, Kuriyama T, Tatsumi K, Kunitomo F, Okita S, Tojima H, Yuguchi Y, and Watanabe S. (1986). Control of ventilation in extreme-altitude climbers. J Appl Physiol 61:500-506.

Moore LG, Niermeyer S, and Zamudio S. (1998). Human adaptation to high altitude: Regional and life-cycle perspectives. Ame J Phys Anthropol Suppl 27:25-64.

Murray MP, Mollinger LA, Gardner GM, and Sepic SB. (1984). Kinematic and EMG patterns during slow, free, and fast walking. J Orthop Res 2:272-280.

Peltonen JE, Kowalchuk JM, Paterson DH, DeLorey DS, duManoir GR, Petrella RJ, and Shoemaker JK. (2007). Cerebral and muscle tissue oxygenation in acute hypoxic ventilatory response test. Respir Physiol Neurobiol 155:71-81.

Peltonen JE, Paterson DH, Shoemaker JK, Delorey DS, Dumanoir GR, Petrella RJ, and Kowalchuk JM. (2009). Cerebral and muscle deoxygenation, hypoxic ventilatory chemosensitivity and cerebrovascular responsiveness during incremental exercise. Respir Physiol Neurobiol 169:24-35.

Poulin MJ, Fatemian M, Tansley JG, O'Connor DF, and Robbins PA. (2002). Changes in cerebral blood flow during and after $48 \mathrm{~h}$ of both isocapnic and poikilocapnic hypoxia in humans. Exp Physiol 87:633-642.

Prommer N, and Schmidt W. (2007). Loss of CO from the intravascular bed and its impact on the optimised co-rebreathing method. Eur J Appl Physiol Occup Physiol 100:383-391.

Prommer N, Thoma S, Quecke L, Gutekunst T, Volzke C, Wachsmuth N, Niess AM, and Schmidt W. (2010). Total hemoglobin mass and blood volume of elite Kenyan runners. Med Sci Sports Exerc 42:791-797.

Pugh LG. (1964). Blood volume and haemoglobin concentration at altitudes above $18,000 \mathrm{ft}$. (5500 M). J Physiol 170: 344-354.

Sahyoun C, Floyer-Lea A, Johansen-Berg H, and Matthews PM. (2004). Towards an understanding of gait control: Brain activation during the anticipation, preparation and execution of foot movements. Neuroimage 21:568-575.

Sato F, Nishimura M, Igarashi T, Yamamoto M, Miyamoto K, and Kawakami Y. (1996). Effects of exercise and CO2 inhalation on intersubject variability in ventilatory and heart rate responses to progressive hypoxia. Eur Resp J 9:960-967.

Saunders PU, Pyne DB, and Gore CJ. (2009a). Endurance training at altitude. High Alt Med Biol 10:135-148.

Saunders PU, Telford RD, Pyne DB, Hahn AG, and Gore CJ. (2009b). Improved running economy and increased hemoglobin mass in elite runners after extended moderate altitude exposure. J Sci Med Sport 12:67-72.

Savourey G, Garcia N, Besnard Y, Guinet A, Hanniquet AM, and Bittel J. (1996). Pre-adaptation, adaptation and deadaptation to high altitude in humans: Cardio-ventilatory and haematological changes. Eur J Appl Physiol Occup Physiol 73:529-535.
Schmidt W, and Prommer N. (2005). The optimised co-rebreathing method: A new tool to determine total haemoglobin mass routinely. Eur J Appl Physiol Occup Physiol 95:486495.

Schoene RB. (1982). Control of ventilation in climbers to extreme altitude. J Appl Physiol 53:886-890.

Schoene RB, Lahiri S, Hackett PH, Peters RMJ, Milledge JS, Pizzo CJ, Sarnquist FH, Boyer SJ, Graber DJ, and Maret KH. (1984). Relationship of hypoxic ventilatory response to exercise performance on Mount Everest. J Appl Physiol Respir Environ Exerc Physiol 56:1478-1483.

Siebenmann C, Robach P, Jacobs RA, Rasmussen P, Nordsborg N, Diaz V, Christ A, Olsen NV, Maggiorini M, and Lundby C. (2012). "Live high-train low" using normobaric hypoxia: A double-blinded, placebo-controlled study. J Appl Physiol 112:106-117.

Subudhi AW, Dimmen AC, and Roach RC. (2007). Effects of acute hypoxia on cerebral and muscle oxygenation during incremental exercise. J Appl Physiol 103:177-183.

Subudhi AW, Lorenz MC, Fulco CS, and Roach RC. (2008). Cerebrovascular responses to incremental exercise during hypobaric hypoxia: Effect of oxygenation on maximal performance. Am J Physiol Heart Circ Physiol 294:H164H171.

Tannheimer M, Fusch C, Böning D, Thomas A, Engelhardt M, and Schmidt R. (2010). Changes of hematocrit and hemoglobin concentration in the cold himalayan environment in dependence on total body fluid. Sleep Breath 14:193-199.

van der Zee P, Cope M, Arridge SR, Essenpreis M, Potter LA, Edwards AD, Wyatt JS, McCormick DC, Roth SC, and Reynolds EO. (1992). Experimentally measured optical pathlengths for the adult head, calf and forearm and the head of the newborn infant as a function of inter optode spacing. Adv Exp Med Biol 316:143-153.

West JB, Lahiri S, Gill MB, Milledge JS, Pugh LG, and Ward MP. (1962). Arterial oxygen saturation during exercise at high altitude. J Appl Physiol 17:617-621.

Address correspondence to: Stephen S. Cheung, PhD Department of Kinesiology Brock University 500 Glenridge Avenue St. Catharines Ontario L2S-3A1 Canada

E-mail: scheung@brocku.ca

Received December 31, 2013, accepted in final form May 15, 2014. 